\title{
La obsolescencia no-programada: una circunnavegación alrededor del testimonio latinoamericano y sus avatares críticos
}

Unplanned Obsolescence: Circumnavigating Latin American Testimonio and Its Critical Avatars

ELZBIETA SKLODOWSKA. esklodow@wustl.edu

Elzbieta Sklodowska se formó como latinoamericanista en Polonia y los Estados Unidos. En la actualidad ocupa la cátedra especial Randolph Family Professorship en Washington University en St. Louis, Missouri. Sus campos de especialidad abordan la narrativa caribeña de los siglos XIX y XX; literatura y cultura cubana; el Período Especial en Cuba; el testimonio hispanoamericano. Ha publicado más de 70 artículos y ha co-editado 5 libros. Sus monografías incluyen: Testimonio hispanoamericano: historia, teoría, poética; La parodia en la nueva novela hispanoamericana (1960-85); Todo ojos, todo oídos: control e insubordinación en la novela hispanoamericana (1895-1935); Espectros y espejismos: Haití en el imaginario cubano. Su libro más reciente, Invento, luego resisto: El Período Especial como experiencia y metáfora (1990-2015), será publicado en 2016 por la Editorial Cuarto Propio (Santiago de Chile).

RECIBIDO: 15 DE SEPTIEMBRE DE 2015

DOI: $10.7203 /$ KAM.6.6921

ACEPTADO: 15 DE OCTUBRE DE 2015

ISSN: 2340-1869

Resumen: Este artículo ofrece un panorama de las diversas formas narrativas que suelen agruparse bajo el rubro de testimonio latinoamericano. Una vez esbozadas las principales corrientes en los debates críticos generados por el testimonio, este artículo concluye con la sugerencia de que las futuras investigaciones han de enfocarse en la reevaluación de los marcos metodológicos a la luz del contexto actual marcado por la globalización, digitalización y el vertiginoso cambio de las nociones de lo real y lo virtual.

Palabras clave: testimonio latinoamericano, crítica del testimonio.

\begin{abstract}
This article offers an overview of the myriad narrative forms grouped under the label of Latin American testimonial discourse (testimonio). After outlining the main currents in the critical debates generated by testimonio, this article also offers some suggestions for further research by calling for an indepth re-evaluation of existing methodological frameworks within the context of globalization, digitalization, and rapidly changing notions of the virtual and the real.
\end{abstract}

Keywords: Latin American testimonio, testimonio criticism. 
Elzbieta Sklodowska. La obsolescencia no-programada...

No hay una sola hermosa palabra, con la excepción dudosa de testigo, que no sea una abstracción.

Jorge Luis Borges, "Prólogo" a La cifra (1981)

Volver a hablar de la (po)ética del testimonio latinoamericano a cincuenta años de la publicación de La biografía de un cimarrón (1966), lamentar la falta de rigor en el manejo del término o adentrarnos, una vez más, en las fisuras entre la experiencia y la narrativización en Me llamo Rigoberta Menchú y así me nació la conciencia (1983) serían ejercicios plausibles, aunque con pocas posibilidades de rendir frutos críticamente productivos. Si aceptamos el dictum de Umberto Eco de que todo texto está plagado de espacios en blanco y, por lo tanto, "vive de la plusvalía de sentido que el destinatario introduce en él” (Eco, 1993: 76), una ojeada a la copiosa bibliografía acerca del testimonio sería suficiente para sugerir que apenas quedan intersticios crítico-interpretativos que no hayan sido rellenados por un artículo, un comentario, un libro, un congreso, una ponencia o una tesis doctoral. Una búsqueda rápida de "testimonio latinoamericano" en Google Scholar produce más de doscientos resultados, mientras que la combinación de "testimonial" y "Latin America" nos lleva instantáneamente a más de seiscientas entradas, en inglés y español. Objeto de incontables polémicas entre autores, lectores, editores y estudiosos, el testimonio latinoamericano ha seguido el rumbo ya previamente recorrido por otros géneros y paradigmas, pasando de la indefinición y confusión a la fascinación, de la canonización a la (auto)disolución en "post-testimonios" (Gugelberger, 1998), de las proclamas y manifiestos a los epitafios escritos en tumbas y mausoleos después de dolorosos y prolongados velorios. Entonces, ¿por qué volver sobre el tema de testimonio?

En el contexto contemporáneo latinoamericano, la compulsión por seguir hablando del testimonio se debe a una confluencia de factores asentados en una profunda relación con la historia literaria y la experiencia histórica. Empezando con la longue durée de la historia de la literatura, en el último tercio del siglo XX el testimonio no solamente pasó “del margen al centro” (Beverley, 1992) sino que suplantó al realismo mágico en tanto paradigma de una expresión "genuinamente" latinoamericana. Desde las entrañas más profundas de Latinoamérica el testimonio cuestionó el estatuto de "literatura", reinventando los parámetros ideo-estéticos de la misma (Rincón, 1978). Lo que Ana Housková ha llamado "conciencia del género testimonio" ha permitido a los críticos discernir todo un linaje testimonial dentro del archivo literario latinoamericano (Housková, 1989: 19). Esta formación de un nuevo tipo de sensibilidad y competencia literaria ha venido acompañada por el desarrollo de un aparato metodológico de carácter interdisciplinario y por la configuración de una especie de lengua franca "que se habla en sectores culturales ampliados y que conecta varias disciplinas” (Montaldo, 2014: 267). A pesar del reconocimiento del papel del testimonio en las transformaciones del pensamiento e imaginario 
Elzbieta Sklodowska. La obsolescencia no-programada...

latinoamericanos, el deseo por seguir reafirmando la importancia del testimonio en tanto discurso identitario, auténtico y original -desde y sobre Latinoamérica - sigue siendo un poderoso catalizador de la producción crítica al respecto.

Tampoco se puede pasar por alto otro fenómeno que era el corolario de la canonización del testimonio, o sea, el profundo cambio en los programas de estudio y en la práctica pedagógica, sobre todo en el sistema educacional norteamericano (Webb, Benz, 1996). Linda Mary Brooks recoge los múltiples hilos de este fenómeno en una síntesis tan útil como sucinta:

In the years since its contemporary debut with Esteben Montejo (1966), the genre known as testimonio has spearheaded the ongoing challenge to Western-based humanities education. The new genre helped launch the idea of "identity politics," upended notions of the "literary masterpiece” and won its foremost author, Rigoberta Menchú, the 1992 Nobel Peace Prize. Even following David Stoll's discovery of Menchú's inaccuracies, the form still dominates much of literary study, as its inclusion in David Damrosch's authoritative recent anthology, What is World Literature?, attests (Brooks, 2005: 181).

Si bien es cierto que el testimonio tiene su "cuarto propio" en América Latina, en el latinoamericanismo y en la historia literaria latinoamericana, no debemos ignorar su inserción dentro de un contexto histórica y geográficamente más amplio. Según el planteamiento de Andreas Huyssen (2007), las corrientes de reivindicación de la "visión de los vencidos" y de la configuración de las historiografías alternativas - que culminaron en los estudios postcoloniales y subalternos de los 90tenían sus raíces treinta años antes, en los movimientos de liberación nacional y postcolonial de los 60 . Las tensiones ideológicas y éticas generadas por la intervención del editor letrado en el proceso de edición y circulación de los testimonios “canónicos” latinoamericanos (Barnet-Montejo; PoniatowskaPalancares; Burgos-Menchú) resonaron no solamente con el impulso contra-hegemónico de las teorías postcoloniales y su cuestionamiento radical de las representaciones europeas del "otro" sino también con todo un acervo de los "posts": postmodernidad, postcomunismo, posthumanidad. De hecho, en las múltiples definiciones del testimonio sobresalen las mismas palabras-clave -marginalidad, representación, poder, subversión, reivindicación- que estaban reverberando en los debates en torno a los estudios postcoloniales, subalternos y culturales en la década de los 90. Asimismo, en la hibridez formal del testimonio - en cuyos intersticios se perfila el discurso psicoanalítico, la confesión, el Bildungsroman, la autobiografía, las historias de vida o hasta la picaresca- es posible discernir los espejeos de aquellos desplazamientos paradigmáticos que, a su vez, catalizaron el impulso interdisciplinario de las corrientes postestructuralistas.

Una vez establecida su "legitimidad" dentro del repertorio de discursos latinoamericanos en las últimas décadas del siglo $\mathrm{XX}$, el testimonio llegó a ser empleado -desde posiciones ideológicas y metodológicas bien diversas- como una herramienta interpretativa. El lente teñido por un matiz 
Elzbieta Sklodowska. La obsolescencia no-programada...

testimonialista fue aplicado indistintamente para abordar discursos en extremo heterogéneos: crónicas coloniales, testimonios indígenas, autobiografías, novelas históricas, narrativa abolicionista, literatura "regionalista", poemas, artículos periodísticos, archivos de las "comisiones de la verdad", diarios, discursos políticos, memorias, historias de vida, películas, deposiciones legales, cartas, confesiones, espectáculos teatrales, obras de arte, artefactos de cultura material, museos, exhibiciones. Basta con citar, a manera de ejemplo, un proyecto relativamente reciente, mencionado por Beatriz Figallo (2013), para darse cuenta tanto de la continua vigencia del papel reivindicador de la fórmula testimonial como de los retos -metodológicos, económicos, ideológicos y formales- que siguen acompañando sus usos y abusos:

El caso de la revista argentina Lucha Armada es interesante. Surgida en 2004 para investigar la experiencia de las organizaciones guerrilleras durante la década del setenta, reconstruyó la experiencia de grupos político-militares que no habían tenido un lugar en el mundo historiográfico, y eran prácticamente desconocidos por casi todos los interesados en aquellos años y sus protagonistas. Con diversidad de documentos e historias de vida, y a través de entrevistas a antiguos militantes, dejó de aparecer tras once números publicados en cuatro años, justificando en que presentarse periódicamente "con materiales de compleja elaboración, que por lo general requieren investigaciones, revisiones y, naturalmente, discusiones”, no resultaba sencillo sin declinar en la calidad de los artículos publicados (Figallo, 2013: 19).

No obstante, sería insuficiente -e injusto- limitarnos a la afirmación de que el testimonio latinoamericano perdura en el horizonte crítico solamente gracias a su amplio margen de indeterminación formal-genérica que permite un crecimiento indiscriminado del corpus primario. En las postrimerías del siglo XX la omnipresencia del testimonio - o del registro testimonial, si optamos por esquivar las trampas terminológicas- es el signo de la extrema urgencia por recordar, recuperar, denunciar y archivar los traumas individuales y colectivos. Términos como "la era del testigo" (Wieviorka, 1998; Hartog, 2005) o la “obsesión con la memoria” (Huyssen, 2007) entran en circulación para designar el carácter epocal, generalizado y sin precedentes de este ímpetu testimonialista más reciente. En Latinoamérica, las profundas secuelas de la represión militar y estatal desde Centroamérica hasta el Cono Sur- se encuentran enmarcadas por el contexto transnacional y transdisciplinario de los estudios sobre el Holocausto, el trauma y la memoria. Al mismo tiempo es importante reconocer el gran crecimiento de aproximaciones teóricas generadas desde las circunstancias específicamente latinoamericanas (Jelin, 2002) y la percepción de que esta “irrupción” del testimonio representa una suerte de "segunda venida" (Bustos, 2010).

Dentro de la crítica literaria del testimonio hay, por cierto, líneas de exégesis donde el agotamiento de las opciones interpretativas resulta tan obvio que, en vez de encontrar un camino, acabamos en un callejón sin salida. Por ejemplo, y dejando aparte todo el escepticismo de la era de los "posts", creo que hoy sería casi imposible agregar algo original al tema de las manipulaciones del testigo 
por parte del editor "letrado". Aunque no se ha perdido del todo la fe en el poder del discurso testimonial en tanto recurso de solidaridad política con el subalterno, sería igualmente difícil argüir que el testimonio mediatizado es un vehículo monolítico - y el más idóneo- para trasvasar el habla a la escritura y dar voz "a los más humillados entre los humillados" (Menchú-Burgos Debray, 1983: 28). Es por las mismas razones - de sobresaturación y obsolescencia- que no me comprometería a dirigir una tesis doctoral centrada en las distinciones entre lo verdadero y lo falso o en el desdibujamiento de los deslindes entre los "géneros" literarios tradicionales. Tampoco podría aceptar un estudio más - nunca el último, siempre el penúltimo- sobre la credibilidad del testigo. Si menciono la dimensión pedagógica del testimonio es porque creo que como profesores no estamos totalmente a salvo de un narcisismo que fija nuestra atención en nuestros propios ombligos y nuestros propios demonios. Además, a pesar de su aparente afán por la innovación crítica, la "máquina de enseñanza” norteamericana -utilizando el término de Gayatri Spivak (2012) - no es del todo inmune a la tentación de perpetuar y "clonar”, en vez de marchar a contrapelo de lo preconcebido.

Finalmente, a los "veteranos" de la crítica testimonial nos incumbe admitir que en medio del vértigo tecnológico que acompaña la eclosión de testimonios audiovisuales y digitales (Hartman 2001) se han abierto derroteros interpretativos que están reduciendo a la obsolescencia no-programada las mismas metodologías que en la antesala del siglo XXI nos parecían tan innovadoras como duraderas. Las indagaciones acerca de los "blogs, fotologs y webcams" en términos de "literatura testimonial" (Sibilia, 2006) o el creciente uso de "narraciones digitales" en la práctica pedagógica de las "nuevas humanidades" (Benmayor, 2008) y en la historia oral (High, 2010) son tan solo algunos de los ejemplos de las reencarnaciones más recientes del paradigma testimonial. No obstante, el contraste más chocante entre los testimonios "canónicos" latinoamericanos y los "blogs, fotologs y webcams" radica en la (auto)configuración de la figura del "testigo". En los nuevos medios, los silencios, las vacilaciones, la resistencia, la intimidad, los "secretos”, las verdades parciales - de Esteban Montejo, Jesusa Palancares o Rigoberta Menchú- quedan suplantados por un espectáculo exhibicionista a ultranza cuyos límites -si es que los hay- aún quedan por ser delineados.

Tal vez es este el momento para replantear mi interrogante inicial y en vez de indagar en "por qué volver a hablar del testimonio”, preguntarnos por dónde y cómo volver. Puesto que siempre resulta más fácil empezar con una negativa, creo que no deberíamos ir por el camino de (auto)indagación nostálgica o ceder a las ominosas consignas sobre la irrelevancia de la labor crítica en las humanidades. Como "veterana" de la crítica testimonial, se supone que soy dueña de una mirada retrospectiva y debería aprovecharla. Por cierto, como cualquier otra perspectiva, esta también refracta la imagen y adolece de puntos ciegos aunque viene acompañada de una (meta)conciencia duramente ganada y fácil de compartir. Una pregunta más se impone de inmediato: ¿sería esta metaconciencia capaz de catalizar (re)lecturas 
Elzbieta Sklodowska. La obsolescencia no-programada...

originales, relevantes e inesperadas? La trayectoria de la crítica testimonial -y digo eso con una pequeña ayuda de Shakespeare- parece sugerir que hay más cosas en el cielo y en la tierra de las que pueda soñar nuestra filosofía. Recordemos que después del auge inicial de la crítica del testimonio a principios de la década de los 90, gradualmente empezaron a surgir "autocorrecciones" o, por lo menos, matizaciones, de parte de aquellos estudiosos que habían contribuido más directamente a la canonización del testimonio. Los mismos críticos que previamente habían considerado como incompatible con sus posturas políticas cualquier gesto que pudiera "desmitificar" el testimonio, dejaron de igualar el escrutinio textual de los textos testimoniales con el peligro de desmantelar la legitimidad de los mismos.

Creo que el primer viraje decisivo en la trayectoria crítica sobre el tema del testimonio latinoamericano ocurrió a raíz del debate desatado por el libro de David Stoll, Rigoberta Menchú and the Story of All Poor Guatemalans (1999). Fuera o no este su objetivo original, el trabajo del antropólogo norteamericano -construido a base de "contrapruebas" recogidas en el curso de entrevistar a 120 personas- llegó a la primera plana de los periódicos bajo el rubro de "contra-testimonio". Se trata de un libro hábilmente compuesto, pero también plagado de omisiones y manipulaciones que han sido desbrozadas en detalle en otras ocasiones (Arias, 2001). Rigoberta Menchú and the Story of All Poor Guatemalans fue un reto mucho más directo a la "veracidad" de Rigoberta Menchú que las interpretaciones antes consideradas como "deconstructivistas". Pero el libro de Stoll no puso fin al testimonio como tal, no desmanteló la denuncia de Rigoberta Menchú ni destruyó a Rigoberta Menchú como testigo, persona y personalidad. La premisa judicial detrás del proyecto del antropólogo norteamericano de que "Un testigo vale lo mismo que ninguno" -reminiscente de Unus testis, nullus testis del derecho romano- podría ser contrarrestada con la afirmación de Carlo Ginzburg (1990) de que un solo testigo - un testigo sólo- es capaz de proporcionar una verdad irrecuperable por otros medios. Pero la polémica con Stoll no me interesa tanto como el impacto de su libro -y del debate que desatósobre las transformaciones dentro del campo de estudio del testimonio.

La táctica de Stoll forzó a los estudiosos del testimonio a revisitar algunas de sus propias estrategias y a buscar nuevos derroteros metodológicos, más allá de los binarismos de ficción/no ficción, oralidad/escritura, manipulación/transparencia, literatura/documento social, solidaridad/ desmitificación. La respuesta más completa y contundente a Stoll apareció en forma del volumen colectivo The Rigoberta Menchú Controversy (2001), editado por Arturo Arias. Pero el giro (meta)crítico se vuelve aún más visible en aquellos trabajos de John Beverley donde el crítico más prominente de la veta "solidaria” en la crítica testimonialista deja de percibir las contradicciones y fisuras en el testimonio de Rigoberta Menchú como una potencial debilidad que necesitaría ser escamoteada, justificada o sacrificada en aras de la política. En la era post-Stoll, la textura de la memoria y la textualidad del relato se convierten para Beverley en emblemas de la autoridad narrativa de Menchú: 
Elzbieta Sklodowska. La obsolescencia no-programada...

Otorgar a narradores testimoniales como Menchú solo la posibilidad de ser "testigos”, pero no el poder de crear su propia autoridad narrativa y negociar sus condiciones de verdad y representatividad sería una manera de decir que el sujeto subalterno puede, por supuesto, hablar, pero solo a través de la autoridad sancionada institucionalmente del periodista o del etnógrafo... (Beverley 2012, 110).

Beverley admite que este nuevo paradigma testimonial que se asoma entre líneas de su relectura no es un vehículo de la verdad, sino de una forma de verdad. Una forma de verdad vivida, tamizada por el trauma, el recuerdo y el olvido y finalmente (re)construída por el testigo a través de una narración repleta de elipsis, saltos, silencios y condensaciones, como cualquier relato. La credibilidad de la/del testimoniante tampoco puede ser absoluta, pero a todo lector solidario le incumbe suspender la incredulidad.

En mi propia labor crítica (Sklodowska, 1995; 2001) también he llegado a matizar la rigidez de algunas de mis aseveraciones forjadas al calor de los primeros debates acerca del testimonio cuando mi inclinación hacia las "tácticas formalistas" acabó ganándome el epíteto de "espíritu de liberalismo político" a la par con el alegato de que el objetivo soterrado de mi trabajo era incorporar el testimonio al "campo de literatura elitista" y de este modo "relativizar su urgencia política y moral” (Reed, 2001). No se trata aquí de reabrir las antiguas polémicas ni de lamentar los deslices de intercomunicación. No obstante, sostengo que algunos de mis análisis tempranos iban por el mismo camino de afirmación de la autoridad discursiva de los testigos que Beverley está planteando en respuesta a Stoll. Mi intención -que por lo visto no logré articular en aquel entonces- era mostrar cómo Esteban Montejo, Rigoberta Menchú, Jesusa Palancares o Domitila Barrios de Chungara iban a contrapelo del paradigma confesional-legal y en vez de una absolución buscaban una afirmación e inscripción de sus experiencias. Por cierto, no fui ni la primera ni la única en perseguir esta línea interpretativa puesto que tanto en el trabajo de Doris Sommer (1991) sobre "los secretos de Rigoberta" como en el estudio de Lucille Kerr (1991) sobre "las mentiras" de Jesusa Palancares el énfasis recaía sobre el poder y el saber de las testimoniantes para manipular su propia enunciación.

No puedo negar que los membretes de elitismo, relativismo y liberalismo político me provocaron cierta incomodidad y hasta una preocupación por mi futuro profesional en la academia norteamericana. Pero tampoco me parecía ético ajustar mi perfil de investigadora y estudiosa de literatura a las exigencias -o las querellas- del momento. Las raíces de mi formación profesional se encuentran en Polonia en los años 70 cuando la notoria "cortina de hierro" ya no era tan impermeable como lo hubieran deseado los que la habían montado para contener, controlar, aislar y subyugar. En aquella época, bajo la perspicaz mirada de mis profesores universitarios de la vieja escuela filológica -muchos de ellos sobrevivientes de la ocupación nazi y del Holocausto, algunos disidentes involucrados en la oposición contra el gobierno comunistaaprendí los rigores de lecturas cimentadas en el análisis textual al mismo tiempo que asimilé las 
Elzbieta Sklodowska. La obsolescencia no-programada...

advertencias sobre los peligros de la abolición del "referente". Mis maestros me inculcaron para siempre la idea de que independientemente de los regímenes - políticos y metodológicos- los críticos literarios tienen el privilegio y el deber de descubrir, desentrañar, analizar y valorar lo estético.

En el último cuarto de siglo, la academia norteamericana ha afinado mi ojo y mi oído de latinoamericanista y me ha brindado no solamente el espacio profesional para leer, enseñar y escribir sino también el privilegio de poder dialogar con colegas, artistas y escritores latinoamericanos. A pesar de -0 tal vez debido a- mi trayectoria algo atípica, fue en los Estados Unidos donde me nació la aguda conciencia de que pertenezco, nolens volens, a ese circuito académico que Antonio Cornejo Polar bautizó como “un latinoamericanismo fuera de Latinoamérica” (1997) y que Mabel Moraña llamó “un latinoamericanismo internacional” (1998: 233). Tengo que reconocer también que en los comienzos de mi carrera norteamericana el fetiche del politeísmo teórico me llevó más de una vez a subyugar mis análisis a moldes demasiado rígidos, en vez de rigurosos. Fue en aquella época cuando presencié el radical cambio del régimen teórico-metodológico catalizado por los estudios culturales, cuyo ascenso ocurrió de manera paralela a la consagración del testimonio. Sin rechazar los logros de esta línea interpretativa comparto el argumento de Beatriz Sarlo (2000) de que ignorar la dimensión estética del texto sería un grave error. Tal vez mi afinidad con el pensamiento de Sarlo se debe a la semejanza entre el modus operandi de mis profesores polacos y la estudiosa argentina. Recordemos que Sarlo deposita la responsabilidad por la "discusión textualizada” en manos de los críticos literarios:

La cuestión estética no es muy popular entre los analistas culturales, porque el análisis cultural es fuertemente relativista y ha heredado el punto de vista relativista de la sociología de la cultura y de los estudios de cultura popular. Sin embargo, la cuestión estética no puede ser ignorada sin que se pierda algo significativo. Porque si ignoramos la cuestión estética estaríamos perdiendo el objeto que los estudios culturales están tratando de construir (como objeto diferente de la cultura en términos antropológicos). Si existe un objeto de los estudios culturales es la cultura definida de un modo diferente a la definición antropológica clásica. Es importante recordar (escribió Hannah Arendt) que el arte y la cultura no son lo mismo (Sarlo, 2000: 239).

Al contemplar los caminos que me llevarían a contestar mi propia pregunta - ¿por dónde y cómo volver al testimonio? - estoy segura de que no podría escoger una ruta que obviara una "discusión textualizada”. En este laberinto de senderos interpretativos que se bifurcan, tanto las conceptualizaciones teóricas de Sarlo como su propia praxis crítica constituyen una guía insoslayable. "Yo pienso que lo político es una dimensión específica del mundo social” -expresó Sarlo en una entrevista- "y que lo simbólico y lo estético lo son también: es cierto que hay cruces permanentes entre ellos, pero son cruces, no una sobreimpresión de todo con todo" (Sarlo, 2001: 115). Con una matización puntual, Sarlo precisó que el acto de otorgar trascendencia a lo cotidiano no es sucedáneo de 
Elzbieta Sklodowska. La obsolescencia no-programada...

lo literario y que, a la inversa, la conciencia de nuestro entorno -existencial, material- tampoco tiene que ser un obstáculo para dilucidar lo estético:

[N]o existe otra actividad humana que pueda colocarnos frente a nuestra condición subjetiva y social con la intensidad y la abundancia de sentidos del arte, sin que esa experiencia exija, como la religión, una afirmación de la trascendencia... [Es] una práctica que se define en la producción de sentidos y en la intensidad formal y moral (Sarlo, 2000: 7).

¿Quién sino la misma Sarlo es la que ha sabido calar, con excepcional profundidad, en los análisis de lo estético para pasar luego a interpretaciones igualmente iluminadoras de prácticas discursivas noartísticas?

En lo que concierne al testimonio per se, Sarlo ha afirmado que "no hay verdad sino una máscara que dice decir la verdad” (Sarlo, 2005: 39). No creo que esta sea una mera provocación para reducir el testimonio a una forma de ficción en primera persona. Más bien se trata de retar a los críticos para que no dejen de perseguir nuevos recursos de "producción de sentidos". En mi propia práctica académica, hace unos años, el descubrimiento tan inesperado como fortuito del concepto de le différend (la diferencia; el diferendo; el desacuerdo) de Jean François Lyotard me ayudó a romper la complacencia que suele acompañar a cualquier ritualización. No quiero presumir que en el curso de los años he aprovechado todas las posibilidades que brinda la teoría de Lyotard, ni tampoco pretendo sugerir que le différend es por dónde y cómo deberíamos volver al testimonio. No obstante, en esta parte final de mi ensayo quiero compartir algunas de mis incursiones en "la discusión textualizada" del testimonio en compañía de le différend.

Lyotard empezó a desarrollar este concepto a principios de los años 80 en respuesta a Robert Faurisson, estudioso del Holocausto, quien adquirió notoriedad con sus alegatos contra la existencia de las cámaras de gas en los campos de exterminio nazis. Los argumentos de Faurisson partían de la imposibilidad de que hubiera testigos para corroborar este hecho. Lyotard concibió le différend en términos de una configuración discursiva -podríamos decir "testimonial” - en la cual la denuncia de un "daño" por parte del "querellante" (o "demandante") se encuentra bajo la triple amenaza de silenciamiento:

Un querellante es alguien que sufrió un daño y que dispone de los medios para probarlo. Se convierte en una víctima si pierde esos medios... En general, el querellante se convierte en una víctima cuando no le es posible ninguna presentación de la sinrazón que dice haber sufrido. Recíprocamente, el "delito perfecto" consistiría no en dar muerte a la víctima o a los testigos (eso significaría agregar nuevos delitos al primero y agravar la dificultado de borrarlo todo), sino en obtener el silencio de los testigos, la sordera de los jueces y la inconsistencia (locura) del testimonio (Lyotard, 1988: 20). 
Elzbieta Sklodowska. La obsolescencia no-programada...

Lyotard fija su mirada en el proceso de reconstrucción de una vivencia traumática y demuestra que la vulnerabilidad del intento testimonial reside en una confluencia simultánea, dinámica y necesaria de varias instancias: el referente (una experiencia traumática); el testigo/querellante resuelto a romper el silencio y narrar esta experiencia; el oyente/destinatario dispuesto a escuchar, creer y difundir el relato; y, finalmente, el lenguaje apto para hacer significar el caso/daño/referente. La fragilidad de este circuito pone al descubierto los mecanismos del testimonio no como un pacto de solidaridad y buena fe entre el testigo y el oyente, sino como una contienda de carácter ético, político, legal y lingüístico: "si uno neutraliza al destinador, al destinatario y al sentido del testimonio, todo es como si no hubiera referente (como si no hubiera daño)" (20). El modelo de Lyotard es de mayor relevancia para cualquier "discusión textualizada" del testimonio debido a su énfasis en la contienda lingüística por asegurar los medios lingüísticos/retóricos para presentar el daño/el caso.

Si pensamos en el enfrentamiento entre Stoll y Menchú a contraluz del argumento de Lyotard, notaremos que el antropólogo norteamericano no niega la existencia del "caso" (el trauma, el crimen de estado). Según Stoll, Menchú no tiene derecho a recordar desde la posición de un testigo ocular (“ella no lo vio"; "ella no estuvo allí") ni tiene la habilidad necesaria para hacer significar su caso. Recurriendo otra vez a la lógica de Lyotard, si la “prueba” ofrecida por Menchú es juzgada como "inadmisible” por Stoll y "si la argumentación que la sostiene es considerada absurda”, entonces la demanda de Menchú/ querellante "queda desestimada, pues la sinrazón de lo que se queja no puede ser probada" (20-21). El verdadero reto del testimonio es (re)construir el daño como presencia sobre un fondo de ausencia: el silencio de los muertos y la pérdida de las huellas materiales. En todo caso, la credibilidad del sobreviviente se enfrenta, inexorablemente, a la incredulidad del oyente. Cabe notar que a pesar de su profunda sofisticación conceptual, el modelo de Lyotard no proporciona suficientes intersticios para acomodar la (meta)dinámica entre las diversas dimensiones de la "autoridad” de Menchú. El "caso" de Menchú emerge desde las entrañas de una experiencia colectiva, se entreteje con su propia competencia como miembro, representante y portavoz de esta comunidad, ostenta su propia falta de transparencia y nos hace ver cómo la experiencia queda tamizada a través de varios filtros: el pudor, el tabú, el silencio, la memoria, el trauma, la lejanía del exilio, el bilingüismo, la etnicidad, la política, la religión, las jerarquías familiares y grupales. La mediación y complicidad de Elizabeth Burgos, su destinatario más inmediato, tampoco es un acto sencillo, pero a diferencia de Stoll, Burgos no invoca "la sinrazón” de su historia ni confunde "el Como sifuera el caso con el Este es el caso" (Lyotard, 1988: 21).

Los desplazamientos forzados de grandes masas de gente, el desmembramiento de la familia repositorio tradicional de la memoria colectiva- y la desintegración de las comunidades campesinas guatemaltecas durante los años de violencia eran fenómenos que afectaron a la circulación y reproducción de datos sobre los destinos individuales, llevando a una dispersión de historias trasmitidas y una ruptura del 
sentido de continuidad entre el pasado y el futuro. Es en este contexto donde las comunidades tradicionales enfrentan por primera vez una disociación entre la reputación de una persona, por un lado, y sus actos y sus palabras, por el otro. Y es precisamente en este intersticio - un posible desajuste entre los acontecimientos y la versión narrada de los hechos- donde Stoll opta por construir su propia (in)versión de los hechos. No es mi propósito restarle valor interpretativo al modelo de Lyotard sino reconocer las limitaciones interpretativas de esta metodología que, como cualquier otra, requiere numerosas circunnavegaciones al texto.

Por otra parte, nuestra circunnavegación alrededor del testimonio y sus avatares críticos nos ha devuelto, como era de esperar -o temer-, a la pregunta que ha ido resonando desde el inicio de estas páginas: ¿por dónde y cómo volver al testimonio? Espero no dejar a mis lectores con la sensación de haber gastado mi tiempo -y el suyo- en un vano ejercicio retórico. Tampoco quiero dejar en vilo la idea acerca de las limitaciones inherentes a las más sofisticadas teorías. De hecho, mi esperanza final es una forma de desesperanza. En la época en que la relevancia de la labor crítica en las humanidades se encuentra bajo sospecha, revisitar desde varios ángulos disciplinarios - literatura, filosofía, historia- el capital simbólico, textual, metafórico y, sobre todo, humano del testimonio latinoamericano tiene que ser un gesto de resistencia cuya “sinrazón” aún queda por ser científicamente comprobada. 
Elzbieta Sklodowska. La obsolescencia no-programada...

\section{Bibliografía citada}

Arias, Arturo, ed. (2001). The Rigoberta Menchú Controversy. Minneapolis: University of Minnesota Press.

Barnet, Miguel (1966). Biografía de un cimarrón. La Habana: Instituto de Etnología y Folklore.

Benmayor, Rina. "Digital Storytelling as a Signature Pedagogy for the New Humanities". Arts and Humanities in Higher Education 7.2 (2008): 188-204.

Beverley, John (2004). Testimonio: On the Politics of Truth. Minneapolis: University of Minnesota Press.

Beverley, John. "Subalternidad y testimonio. En diálogo con Me llamo Rigoberta Menchú y así me nació la conciencia, de Elizabeth Burgos (con Rigoberta Menchú)”. Nueva Sociedad 238 (marzo-abril de 2012): 102-113.

Beverley, John (1992). "The Margin at the Center: On Testimonio (Testimonial Narrative)". DeColonizing the Subject: The Politics of Gender in Women's Autobiography. Eds. Sidonie Smith, Julia Watson. Minneapolis: University of Minnesota Press: 91-114.

Borges, Jorge Luis (1982). “Prólogo”. La cifra. Buenos Aires: Emecé.

Brina, Maximiliano. "El testimonio contra sí mismo: una lectura de El padre mío de Diamela Eltit". Papeles de trabajo: literatura latinoamericana del Instituto de Literatura Hispanoamericana, Universidad de Buenos Aires 5 (1997): s/n.

Brooks, Linda Mary. "Testimonio's Poetics of Performance”. Comparative Literature Studies 42.2 (2005): 180-222.

Bustos, Guillermo. "La irrupción del testimonio en América Latina: intersecciones entre historia y memoria. Presentación del dossier. Memoria, historia y testimonio en América Latina”. Historia Crítica 40 (2010): 10-19.

Craps, Stef (2013). Postcolonial Witnessing: Trauma out of Bounds. New York: Palgrave Macmillan.

Cornejo Polar, Antonio. "Mestizaje e hibridez: los riesgos de las metáforas. Apuntes". Revista Iberoamericana 180 (1997): 341-344

Eco, Humberto (1993). Lector in fabula. Barcelona: Gedisa. 
Elzbieta Sklodowska. La obsolescencia no-programada...

Figallo, Beatriz. "La historia reciente de América Latina. Entre la complejidad y la incertidumbre, los testimonios”. Revista de Estudios Latinoamericanos 5.10 (Universidad de Valparaíso, Chile, 2013): 9-24.

Ginzburg, Carlo. "Sólo un testigo (Just One Witness)". Historia, Antropología y Fuentes Orales 38 (2007): 5-21.

Gugelberger, Georg M., ed. (1996). The Real Thing: Testimonial Discourse and Latin America. Durham, NC: Duke University Press.

Gugelberger, Georg M. "Remembering the Post-Testimonio: Memoirs of Rigoberta Menchú Tum”. Latin American Perspectives 25.6 (1998): 62-68.

Hartman, Geoffrey. "Tele-suffering and Testimony in the Dot Com Era". Visual Culture and the Holocaust (2001): 111-24.

Hartog, François. “El testigo y el historiador”. Estudios Sociales 21.1 (2005): 9-28.

High, Steven. "Telling Stories: A Reflection on Oral History and New Media”. Oral History 38.1 (2010): 101-112.

Housková, Ana. "El testimonio como género literario”. Ibero-Americana Pragensia 22 (1989): 11-20.

Huyssen, Andreas (2007). En busca del futuro perdido. Cultura y memoria en tiempos de globalización. México: Fondo de Cultura Económica.

Jelin, Elizabeth (2002). Los trabajos de la memoria: Madrid: Siglo XXI de España Editores.

Kerr, Lucille. "Gestures of Authorship: Lying to Tell the Truth in Elena Poniatowska's Hasta no verte Jesús mío". MLN 106 (1991): 370-394.

López, Xesqui Castañer. “Género y postcolonialismo en la creación videográfica: mujeres que escriben con la cámara y seducen en la pantalla”. Dossiers Feministes 18 (2014): 259-276.

Laub, Dori (1992). “An Event without a Witness: Truth, Testimony and Survival”. Testimony: Crises of Witnessing in Literature, Psychoanalysis, and History. Felman, Shoshana y Dori Laub (eds.). New York, Routledge: 75-92.

Lyotard, Jean François (1988). La diferencia. Barcelona: Gedisa.

Menchú, Rigoberta y Elisabeth Burgos-Debray (1983). Me llamo Rigoberta Menchú y así me nació la conciencia. La Habana: Casa de las Américas. 
Elzbieta Sklodowska. La obsolescencia no-programada...

Montaldo, Graciela. “Teoría en fuga”. El taco en la brea 1.1 (2014): 262-276.

Moraña, Mabel (1998). "El Boom del subalterno”. Castro-Gómez, Santiago y Mendieta, Eduardo (eds.). Teorías sin disciplina. Latinoamericanismo, poscolonialidad y globalización en debate. México: Miguel Ángel Porrúa: 233-243.

Poniatowska, Elena (1969). Hasta no verte Jesús mío. México: Era.

Reed, Malcolm. "Tale of Two Academies: John Beverley and Juan Carlos Rodríguez”. HiperFeira: Artes and Literature International.Journal 1 (2001).

Rincón, Carlos (1978). El cambio en la noción de literatura. Bogotá: Instituto Colombiano de Cultura.

Sarlo, Beatriz (1994). Escenas de la vida posmoderna: Intelectuales, arte y videocultura en la Argentina. Buenos Aires: Ariel.

Sarlo, Beatriz (2000). "Los estudios culturales y la crítica literaria en la encrucijada valorativa”. Mojica, Sarah (eds.). Culturas híbridas-No simultaneidad-Modernidad periférica. Mapas culturales para la América Latina. Berlin: Wissenschaftlicher Verlag Berlin: 231-240.

Sarlo, Beatriz (2005). Tiempo pasado. Cultura de la memoria y giro subjetivo. Una discusión. Buenos Aires: Siglo XXI Editores Argentina.

Sarlo, Beatriz. "Entrevista a Beatriz Sarlo (por Edgardo Dobl)”. Cuadernos Hispanoamericanos 618 (diciembre 2001): 111-20.

Sibilia, Paula. "Blogs, fotologs, videologs y webcams: intimidades confesionales en la Web”. Revista de la Sociedad Argentina de Psicoanálisis 9 (2006): 207-220.

Sklodowska, Elzbieta (2001). "The Poetics of Remembering, the Politics of Forgetting: Rereading I, Rigoberta Menchú". Arias, Arturo (ed.). The Rigoberta Menchú Controversy. Minneapolis: University of Minnesota Press: 251-269.

Sklodowska, Elzbieta. “'Con indiscreta curiosidad les pregunté...’: El discurso heterólogo en La vorágine”. Revista de crítica literaria latinoamericana (1995): 193-211.

Sommer, Doris. “Rigoberta's Secrets”. Latin American Perspectives (1991): 32-50.

Spivak, Gayatri Chakravorty (2012). Outside in the Teaching Machine. New York: Routledge.

Stoll, David (1999). Rigoberta Menchú and the Story of All Poor Guatemalans. Boulder, Colo: Westview Press. 
Elzbieta Sklodowska. La obsolescencia no-programada...

Webb, Allen y Stephen C. Benz (1996). Teaching and Testimony: Rigoberta Menchú and the North American Classroom. Albany: State University of New York Press.

Wieviorka, Annette (1998). L'ère du témoin. París: Plon. 